\title{
Associations between genomic merit for daughter pregnancy rate of Holstein cows and metabolites postpartum and estrus characteristics
}

\author{
Ricardo C. Chebel ${ }^{1,2 *}$ (미 and Anderson Veronese ${ }^{1}$ \\ ${ }^{1}$ Department of Large Animal Clinical Sciences, University of Florida, Gainesville 32610 \\ ${ }^{2}$ Department of Animal Sciences, University of Florida, Gainesville 32608
}

\begin{abstract}
Genetic selection of Holstein cattle in the past 2 decades has seen an increased attention to fertility traits. Our hypotheses were that genomic merit for daughter pregnancy rate (GDPR) is positively associated with metabolic responses, hazard of estrus, and estrus characteristics. Pregnant heifers $(\mathrm{n}=821)$ from one herd that were genotyped within 2 mo of birth (Clarifide, Zoetis, Parsippany, NJ) were fitted with automated monitoring devices (SCR Inc., Netanya, Israel) $-21 \pm$ $14 \mathrm{~d}$ relative to calving. Estrus characteristics recorded from calving to $62 \mathrm{~d}$ postpartum were evaluated. Blood samples were collected weekly from a subsample $(\mathrm{n}=$ 499) of cows, from 7 to $28 \mathrm{~d}$ postpartum, for determination of insulin-like growth factor-1, glucose, and nonesterified fatty acids. Cows received artificial insemination or embryo transfer following detected estrus and those not detected in estrus were submitted to an ovulation synchronization protocol starting at $75 \mathrm{~d}$ in milk. Linear and quadratic associations between GDPR and outcomes were analyzed, but when appropriate, results are presented according to GDPR quartile (Q1 = -1.8 to $0.8 ; \mathrm{Q} 2=0.9$ to $1.7 ; \mathrm{Q} 3=1.8$ to $2.5 ; \mathrm{Q} 4=2.6$ to 5.9) based on the parameter estimates of the multivariable models. Genomic merit for daughter pregnancy rate was positively associated with insulin-like growth factor-1 $(\mathrm{Q} 1=24.3 \pm 0.2 ; \mathrm{Q} 2=26.8 \pm 0.2 ; \mathrm{Q} 3=28.2$ $\pm 0.2 ; \mathrm{Q} 4=30.6 \pm 0.3 \mathrm{ng} / \mathrm{mL})$ and glucose $(\mathrm{Q} 1=67.0$ $\pm 0.1 ; \mathrm{Q} 2=69.1 \pm 0.2 ; \mathrm{Q} 3=69.6 \pm 0.2 ; \mathrm{Q} 4=70.8 \pm$ $0.2 \mathrm{mg} / \mathrm{dL}$ ) concentrations, but GDPR was negatively associated with nonesterified fatty acid concentration $(\mathrm{Q} 1=281.2 \pm 4.9 ; \mathrm{Q} 2=262.0 \pm 5.9 ; \mathrm{Q} 3=239.3 \pm$ $5.0 ; \mathrm{Q} 4=221.6 \pm 4.7 \mu \mathrm{mol} / \mathrm{L})$. A positive association was observed between GDPR and hazard of estrus [adjusted hazard ratio and 95\% confidence interval $=1.16$ $(1.06,1.28)]$ and number of estrus events $(\mathrm{Q} 1=0.50 \pm$ $0.03 ; \mathrm{Q} 2=0.62 \pm 0.04 ; \mathrm{Q} 3=0.74 \pm 0.05 ; \mathrm{Q} 4=0.86$
\end{abstract}

Received January 15, 2020.

Accepted June 23, 2020

*Corresponding author: rcchebel@ufl.edu \pm 0.06 ) within $62 \mathrm{~d}$ postpartum, duration of estrus (Q1 $=14.10 \pm 0.04 ; \mathrm{Q} 2=14.48 \pm 0.04 ; \mathrm{Q} 3=14.67 \pm 0.04$; $\mathrm{Q} 4=14.98 \pm 0.04 \mathrm{~h})$, probability of activity peak $(0=$ no estrus, $100=$ maximum activity) $\geq 86$ (Q1 $=0.80 \pm$ $0.03 ; \mathrm{Q} 2=0.83 \pm 0.02 ; \mathrm{Q} 3=0.83 \pm 0.03 ; \mathrm{Q} 4=0.85 \pm$ 0.2 ), and probability of heat index $\geq 86$ (Q1 $=0.77 \pm$ $0.04 ; \mathrm{Q} 2=0.81 \pm 0.05 ; \mathrm{Q} 3=0.83 \pm 0.03 ; \mathrm{Q} 4=0.86$ $\pm 0.03)$. Conversely, GDPR was negatively associated with rumination nadir at estrus $(\mathrm{Q} 1=-35.5 \pm 0.1$; $\mathrm{Q} 2=-37.0 \pm 0.1 ; \mathrm{Q} 3=-38.0 \pm 0.1 ; \mathrm{Q} 4=-39.6 \pm$ $0.1 \mathrm{~min})$. We detected a positive association between GDPR and hazard of pregnancy (adjusted hazard ratio $=1.11,95 \%$ confidence interval $=1.03,1.19)$. Selection for GDPR may improve the hormonal and metabolic status of cows postpartum, leading to earlier resumption of cyclicity, and may improve detection of estrus in commercial herds because it was positively associated with estrus characteristics.

Key words: daughter pregnancy rate, estrus behavior, Holstein, genomic merit

\section{INTRODUCTION}

A significant decline in the reproductive efficiency in US dairy herds from the 1970s to the early 2000s has been observed. Among the leading causes associated with the reduced fertility of the modern dairy cows are genetic selection for milk yield while neglecting other traits (Lucy, 2007), delayed resumption of ovulation postpartum and incidence of health disorders (Santos et al., 2010), and unfavorable environmental conditions (Britt et al., 1986; Vailes and Britt, 1990; Palmer et al., 2010; De Rensis et al., 2015). Reproductive management of dairy cows has advanced significantly in the past $20 \mathrm{yr}$ with the advent of ovulation synchronization protocols and, more recently, the incorporation of fertility and longevity traits into genetic selection programs. The national average for 21-d pregnancy rate, however, remains below 20\% (Dairy Records Management Systems, 2016). This is in part due to the low penetration of ovulation synchronization protocols in dairy operations $(<40 \%)$ and inefficient estrus detection (often 
$<60 \%$ ), which delay insemination after calving and reinsemination of cows that fail to conceive.

Since the early 2000s, a halt in the negative trend of reproductive efficiency of dairy cattle has been observed and it is believed to be associated with the inclusion of daughter pregnancy rate (DPR) in dairy cattle selection programs (Norman et al., 2009; García-Ruiz et al., 2016). Daughter pregnancy rate is a measure of genetic merit associated with the expected differences in 21-d pregnancy rate when comparing the daughter of a sire to a population (AIPL, 2013). Twenty-one day pregnancy rate is a function of 21-d insemination rate (rate of insemination of nonpregnant cows) and pregnancy per service $(\mathbf{P} /$ Serv; proportion of cows that become pregnant after a service). The average 21-d insemination rate in US dairy herds is approximately 46\% (Dairy Records Management Systems, 2016) and it is often smaller in herds that limit the use of exogenous hormones for reproductive management. Suboptimal 21-d insemination rates are a consequence of health disorders early postpartum (Rutherford et al., 2016; Santos et al., 2016), management practices (Britt et al., 1986; Vailes and Britt, 1990; Palmer et al., 2010), and physiological changes in high producing cows (Lyimo et al., 2000; Lopez et al., 2004; Aungier et al., 2015). Importantly, a recent experiment demonstrated that duration of estrus was positively associated with the likelihood of pregnancy (Burnett et al., 2017), suggesting that enhanced estrus behavior improves reproductive performance of lactating dairy cows by increasing 21-d insemination rates and, possibly, $\mathrm{P} /$ Serv.

Estrus behavior is a consequence of an orchestrated sequence of events that lead to the acceptability of the male by the female. In a recent study, we demonstrated that genomic merit for DPR (GDPR) was positively associated with the duration of and the likelihood of activity peak $(0=$ no estrus, $100=$ maximum activity) $\geq 80$ at $\mathrm{PGF}_{2 \alpha}$-induced estrus and was negatively associated with rumination nadir at $\mathrm{PGF}_{2 \alpha}$-induced estrus (Veronese et al., 2019a). Furthermore, heifers with elevated GDPR had greater estradiol concentration within $24 \mathrm{~h}$ after onset of $\mathrm{PGF}_{2 \alpha}$-induced estrus and larger ovulatory follicles (Veronese et al., 2019b). Similarly, Irish cows in the top $20 \%$ in genetic merit for calving interval (CIN) had longer duration of estrus and greater activity during estrus compared with cows in the bottom 5\% in genetic merit for CIN (Cummins et al., 2012a). These results demonstrate that cattle with elevated genetic merit for fertility traits are more likely to have estrus behavior and pre-ovulatory hormonal profile that are commonly associated with greater likelihood of pregnancy establishment and maintenance.

The hypotheses of this study were that elevated GDPR is positively associated with IGF-1 concentra- tions postpartum, resumption of ovarian cycles, hazard of estrus, and intensity of estrus. A secondary hypothesis of our study was that GDPR is positively associated with the hazard of pregnancy. The objectives of the current study were to determine the association between GDPR and occurrence of estrus postpartum, estrus characteristics, and IGF-1 concentration postpartum. Additionally, we aimed to describe the association between GDPR and hazard of service and P/Serv.

\section{MATERIALS AND METHODS}

All procedures involving animals were approved by the animal care and use committee of the University of Florida (protocol \#201609559).

\section{Animals, Housing, and Management}

Holstein heifers $(\mathrm{n}=821)$ from one commercial herd born between March and October of 2015 were genotyped within 2 mo of birth using a 50k SNP platform commercially available (Clarifide, Zoetis, Parsippany, NJ). In the current study, we used the GDPR, genomic merit for cow conception rate (GCCR) and genomic merit for milk yield (GMY) data recorded within 2 mo of birth to ensure that phenotypic reproductive performance did not influence genomic estimates. Heifers were housed in group pens within a naturally ventilated barn from birth to weaning (approximately $56 \mathrm{~d}$ of age) and in dry lots with natural shade and no artificial heat abatement from weaning until approximately 30 d before expected calving date. Starting at 10 mo of age, heifers were fed twice daily a TMR formulated to meet or exceed the nutritional requirements of Holstein heifers weighing $\geq 340 \mathrm{~kg}$ of $\mathrm{BW}$ and gaining 800 to $1,000 \mathrm{~g}$ of BW per day (NRC, 2001). During the last $60 \mathrm{~d}$ of gestation, heifers were fed, twice a day, a TMR formulated to meet or exceed the nutritional requirements of pregnant Holstein heifers gaining 900 to 1,200 $\mathrm{g}$ of BW per day (NRC, 2001).

Heifers were moved to a sand-bedded freestall pen in a naturally ventilated barn $30 \mathrm{~d}$ before expected calving date. Heifers demonstrating signs of calving (discomfort, restlessness, tail twitching, and visualization of the allantoic sac through the vulva) were moved to a loose housing sand-bedded pen. Within $12 \mathrm{~h}$ after calving, cows were moved to a postpartum pen (1 to $21 \mathrm{~d}$ postpartum) for daily observation and diagnosis of postpartum diseases. After calving, all cows were housed in freestall sand-bedded pens in 1 of 4 tunnel ventilated barns according to their stage of lactation. In the current study, cows calved between December 2016 and December 2017. After calving, cows were fed thrice daily a TMR to meet or exceed the nutritional 
requirements of Holstein cows producing $40 \mathrm{~kg} / \mathrm{d}$ of $3.5 \%$ FCM (NRC, 2001).

Daily average temperature and humidity from the meteorological station at the Gainesville airport, located approximately 40 miles $(64 \mathrm{~km})$ east of the dairy, were used to calculate daily temperature-humidity index (THI). The percentage of days during the first 60 d postpartum with average THI $\geq 68$ was calculated for each cow.

\section{Automated Estrus-Detection Device, Estrus Characteristics, Rumination, and Activity}

At approximately $30 \mathrm{~d}$ before expected calving date, an automated estrus-detection device (Heat Rumination Long Distance, SCR Inc., Netanya, Israel) mounted on a collar was fitted on the left cranial area of the neck of all heifers. The device determined activity and rumination through an accelerometer. Activity and rumination data were recorded in 2-h intervals. Estrus was determined according to changes in patterns of activity and rumination within a 2 -h interval compared with the average activity and rumination of the same period in the previous 5 and $7 \mathrm{~d}$, respectively (DataFlow2, SCR Inc.). Based on the intensity of changes in activity and rumination, an internal algorithm (DataFlow2, SCR Inc.) calculated the heat index $(0=$ no estrus to $100=$ maximum estrus intensity). Heat index, activity peak $(0=$ no estrus, $100=$ maximum activity $)$, and rumination nadir (maximum difference in rumination time within a 2-h period during estrus compared with the average rumination of the same period in the previous 7 d) were recorded for all estrus events. Study personnel evaluated each activity graph individually and determined the time of onset (2-h period when the activity threshold was surpassed) and end (2-h period when the activity change was below the activity threshold) of estrus and the duration of estrus was calculated (interval from onset to the end of estrus). Activity threshold was set at 3 -fold above the average activity for the same period in the previous $5 \mathrm{~d}$. Automated estrus-detection devices were removed from cows that were deemed not eligible to be serviced, were pregnant at $87 \pm 3 \mathrm{~d}$ after service, left the herd, or were not pregnant by 150 DIM. Daily rumination and activity data from -14 to 28 DIM were collected.

\section{Reproductive Management and Pregnancy Diagnoses}

According to the genetic improvement program of the dairy, 153 cows were selected to be embryo donors and were subjected to a superstimulation protocol (start of superstimulation protocol $=63$ to 94 DIM). Following the embryo collection, these cows were subjected to a timed AI protocol and were inseminated. One hundred seventeen cows did not receive a first service because they left the herd or were deemed ineligible for service by the herd manager. In total, 526 cows received AI and 245 cows received embryo transfer for first service. Cows were monitored for signs of estrus based on the automated estrus-detection device and visually (standing to be mounted, mounting other cows, bellowing, increased nervousness and activity, walking fence line, swelling and reddening of the vulva, and vaginal mucous discharge) with the aid of a mount detection device applied to the tail-head (Estrotect, Rockway Inc., Spring Valley, WI). Cows determined to be in estrus were serviced $(\mathrm{n}=398)$ and those not detected in estrus were enrolled in an ovulation synchronization protocol (Ovsynch, $\mathrm{n}=373$ ) for first service. The Ovsynch (GnRH, $\mathrm{PGF}_{2 \alpha} 7$ d later, GnRH 2.5 d later, and timed AI $16 \mathrm{~h}$ later) started at 75 DIM. Following the first service, cows detected in estrus were serviced $(\mathrm{n}=372)$ and those cows diagnosed not pregnant were enrolled in the Ovsynch protocol $(\mathrm{n}=73)$. All cows were examined for pregnancy by palpation per rectum of the uterine contents $38 \pm 3 \mathrm{~d}$ after service. Pregnant cows were re-examined by palpation per rectum of the uterine contents $87 \pm 3 \mathrm{~d}$ after service. Three hundred twelve cows received AI and 133 cows received embryo transfer for the second service. Data regarding sire of service, service technician, and reproductive outcomes were collected from the on-farm software (PCDART, Dairy Records Management System, Chapel Hill, NC).

\section{Blood Samples and Laboratory Assays}

A subsample of cows $(n=499)$ had blood samples collected at 7, 14, 21, and 28 DIM. We selected the cows randomly within week of calving and quartile of GDPR. Blood was sampled by puncture of the coccygeal vein or artery into evacuated tubes containing K2 EDTA (Vacutainer, Becton Dickinson, Franklin Lakes, NJ). Immediately upon collection, tubes were placed on ice and transported to the laboratory for processing within 2 to $3 \mathrm{~h}$ of collection. Blood tubes were centrifuged at $1,500 \times g$ for $15 \mathrm{~min}$ at $4^{\circ} \mathrm{C}$. Aliquots of plasma were frozen at $-80^{\circ} \mathrm{C}$ until assayed. Concentrations of IGF-1 were determined by a commercial ELISA kit (Quantikine ELISA Human IGF-1 Immunoassay, R\&D Systems, Minneapolis, MN) designed for human IGF-1 with $100 \%$ cross-reactivity with bovine IGF-1 (Ribeiro et al., 2014) and the intraassay CV was $8.0 \%$. Serum concentrations of glucose, nonesterified fatty acid (NEFA), and BHB were measured using the RX Daytona bench clinical chemistry analyzer using 
commercial kits (Randox Laboratories Ltd., Charles Town, WV).

\section{Clinical Examination, Disease Definition, BCS, and Milk Yield}

Cows delivering twins and stillborn calves and cows with calving difficulty $\geq 2$ were classified as having calving problems. Farm personnel were trained to examine cows within $24 \mathrm{~h}$ after calving to diagnose and record the occurrence of retained fetal membranes (Kelton et al., 1998). Additionally, all cows were examined by trained farm personnel at 4, 7, and 10 DIM for the diagnosis of metritis, which was defined as watery, pink/brown, and fetid vaginal discharge (Chenault et al., 2004). All cows were observed once daily by farm personnel for general health and thrice daily, during milking, for mastitis. Mastitis was defined as altered milk and redness and firmness of the udder. Displacement of abomasum was defined as a metallic sound during auscultation and percussion between the 7th and 13th intercostal space on the left or right side. Incidences of displacement of abomasum and mastitis within $60 \mathrm{~d}$ postpartum were recorded. Cows diagnosed with at least one of the diseases described previously were classified as morbid. Cows with $\mathrm{BHB}$ concentrations $\geq 1,200 \mu \mathrm{mol} / \mathrm{L}$ in at least one blood sample were considered positive for subclinical ketosis (Duffield et al., 2009). Percentage of cows removed from the herd (death/culling) during the first $60 \mathrm{~d}$ postpartum was calculated.

Cows were scored for body condition at enrollment and at $3 \pm 3$ and $63 \pm 3$ DIM $(1=$ emaciated and 5 = obese; 0.25 unit increments; Ferguson et al., 1994). Cows were milked thrice daily. Daily milk weights were recorded and weekly average milk weights were collected from PCDART (Dairy Records Management System). The average milk yield in the first $14 \mathrm{wk}$ postpartum (AMY14W) and the total milk yield up to 14 wk postpartum were used in this study.

\section{Statistical Analysis}

This was a prospective observational study. Data were analyzed using SAS version 9.3 (SAS Institute Inc., Cary, NC). We analyzed continuous variables by ANOVA using the GLM or MIXED procedure. Data were evaluated for normality and homogeneity of residuals after fitting the model. We analyzed binary data by logistic regression using the LOGISTIC procedure. Time-dependent variables were analyzed by the Cox proportional hazard ratio using the PHREG procedure and the interval to an event (e.g., estrus, pregnancy) was analyzed by the Wilcoxon test of equality using the LIFETEST procedure.
We analyzed the associations between cow class (artificially inseminated, embryo recipient, embryo donor) and GDPR, GCCR, GMY, and genomic merit for productive life and net merit by ANOVA using the GLM procedure. The model only included cow class. The contrasts between artificially inseminated cows versus embryo recipients and between artificially inseminated + embryo recipients versus embryo donors were evaluated and reported (Supplemental Table S1; https://doi .org/10.3168/jds.2020-18207).

Estrus events occurring $\leq 62$ DIM were used for the statistical analyses. Duration of estrus and rumination nadir were normally distributed, whereas activity peak and heat index were skewed to the right. Therefore, we classified each estrus event as having activity peak $<86$ or $\geq 86$ and heat index $<86$ or $\geq 86$ and analyzed them using logistic regression. Because several cows had multiple estrus recorded before the collar was removed or before they became pregnant, we analyzed estrus characteristics as repeated measures with cow as the random effect and estrus event (first, second, third, and so on) and DIM at estrus as fixed effects. Additionally, 403 cows were detected in estrus between 42 and 62 DIM and the characteristics of the first estrus recorded within this period were analyzed because in a herd with a 42 DIM voluntary waiting period the first estrus recorded between 42 and 62 DIM would be used to inseminate the cows.

Genomic merit for DPR (linear and quadratic), GMY (linear and quadratic), and their interaction were included in all models. In addition, we included in all models whether or not cows were subjected to a superovulation protocol (yes vs. no). For each of the outcomes evaluated, univariable analyses were conducted to determine whether other explanatory variables (BCS at calving, percentage of days during the first $60 \mathrm{~d}$ postpartum with average THI $\geq 68$, calf sex, morbidity, ketosis, AMY14W) should be included in the multivariable model $(P \leq 0.10)$. Continuous variables were tested for their linear and quadratic effects. We included type of service (insemination vs. embryo transfer), reason to service (estrus vs. ovulation synchronization protocol), and their interaction with GDPR in the models to analyze hazard of service, DIM at first service, $\mathrm{P} /$ Serv, pregnancy loss, and hazard of pregnancy. To analyze the association between GDPR and hazard of service (first and second), cows with first service $\geq 85$ DIM and cows with second service $\geq 35 \mathrm{~d}$ after the first service were censored.

For each of the multivariable models, collinearity was tested using the REG procedure with the "collin" and "VIF" functions. Variables with variance inflation factors $\geq 1.5$ were considered collinear. Collinearity was observed between GDPR and GCCR for all outcomes 
Table 1. Mean genomic merit and health and performance responses of primiparous Holstein cows according to genomic merit for daughter pregnancy rate $(\mathrm{DPR})$

\begin{tabular}{|c|c|c|c|c|c|}
\hline \multirow[b]{2}{*}{ Variable $( \pm$ SEM $)$} & \multicolumn{4}{|c|}{ Genomic merit for DPR quartile $(\mathrm{Q})^{1}$} & \multirow[b]{2}{*}{$P$-value ${ }^{2}$} \\
\hline & $\mathrm{Q} 1(\mathrm{n}=234)$ & $\mathrm{Q} 2(\mathrm{n}=237)$ & Q3 $(\mathrm{n}=205)$ & $\mathrm{Q} 4(\mathrm{n}=215)$ & \\
\hline Genomic merit for cow conception rate & $1.02 \pm 0.06$ & $2.24 \pm 0.05$ & $3.09 \pm 0.05$ & $4.25 \pm 0.07$ & $<0.01$ \\
\hline Genomic merit for milk yield & $1,233.8 \pm 30.7$ & $1,013.7 \pm 30.4$ & $943 \pm 34.4$ & $736.5 \pm 31.6$ & $<0.01$ \\
\hline Genomic merit for productive life & $3.5 \pm 0.1$ & $4.4 \pm 0.1$ & $5.2 \pm 0.1$ & $5.9 \pm 0.1$ & $<0.01$ \\
\hline Genomic merit for net merit & $483.6 \pm 9.2$ & $483.3 \pm 8.9$ & $523 \pm 9.9$ & $521.1 \pm 8.6$ & $<0.01$ \\
\hline Uterine diseases, $\%$ & $18.8 \pm 2.6$ & $24.1 \pm 2.8$ & $23.8 \pm 3.0$ & $23.1 \pm 2.9$ & $0.08^{3}$ \\
\hline Ketosis, \% (n) & $3.0 \pm 1.3(168)$ & $1.0 \pm 1.0(97)$ & $0.8 \pm 0.8(127)$ & $0.8 \pm 0.8(119)$ & 0.11 \\
\hline Lameness within 60 DIM, \% & $6.2 \pm 1.7$ & $3.6 \pm 1.2$ & $3.1 \pm 1.3$ & $4.1 \pm 1.4$ & 0.32 \\
\hline Mastitis within 60 DIM, \% & $4.8 \pm 1.5$ & $7.2 \pm 1.7$ & $4.1 \pm 1.4$ & $6.1 \pm 1.7$ & 0.95 \\
\hline Removed within 60 DIM, \% & $10.7 \pm 2.0$ & $5.9 \pm 1.5$ & $5.9 \pm 1.6$ & $8.4 \pm 1.9$ & 0.32 \\
\hline Morbidity within 60 DIM, $\%$ & $37.3 \pm 3.4$ & $43.9 \pm 3.3$ & $35.2 \pm 3.4$ & $38.1 \pm 3.5$ & 0.79 \\
\hline $\begin{array}{l}\text { BCS prepartum }(-12.7 \pm 0.3 \text { d relative } \\
\text { to calving) }\end{array}$ & $3.51 \pm 0.01$ & $3.51 \pm 0.01$ & $3.51 \pm 0.01$ & $3.51 \pm 0.01$ & 0.74 \\
\hline Total milk yield ( $14 \mathrm{wk}), 10^{3} \times \mathrm{kg}$ & $3.45 \pm 0.06$ & $3.42 \pm 0.06$ & $3.38 \pm 0.06$ & $3.43 \pm 0.06$ & 0.47 \\
\hline
\end{tabular}

${ }^{1}$ Genomic merit for DPR: $\mathrm{Q} 1=-1.8$ to $0.8 ; \mathrm{Q} 2=0.9$ to $1.7 ; \mathrm{Q} 3=1.8$ to 2.5 ; $\mathrm{Q} 4=2.6$ to 5.9 .

${ }^{2}$ Referent to the results of the multivariable analyses in which genomic merit for DPR was used as a continuous variable and tested for its linear and quadratic associations with the outcomes of interest.

${ }^{3}$ Quadratic association.

${ }^{4} \triangle \mathrm{BCS}=\mathrm{BCS}$ change.

(variance inflation factor $>4.5$ ); thus, we only included GDPR in the statistical models.

In all models, a backward stepwise elimination procedure was adopted and variables with $P>0.10$ were removed until all variables that remained in the model had $P \leq 0.10$. Statistical significance was considered at $P \leq 0.05$ and a tendency was considered when $0.05<$ $P \leq 0.10$.

Data are reported as least squares means \pm standard error of the means, unless otherwise stated. When appropriate, heifers were categorized into quartiles of GDPR (quartile $1=-1.8$ to 0.8 ; quartile $2=0.9$ to 1.7 ; quartile $3=1.8$ to 2.5 ; quartile $4=2.6$ to 5.9 ) and GMY (quartile $1=-531$ to 628 ; quartile $2=631$ to 987; quartile $3=988$ to 1,349 ; quartile $4=1,353$ to $2,544 \mathrm{~kg}$ ) to report the results based on the parameter estimates of the multivariable analyses.

\section{RESULTS}

Genomic merit for DPR and GCCR were positively correlated $\left[\mathrm{GDPR}=(0.7793 \times \mathrm{GCCR})-0.3865 ; \mathrm{R}^{2}\right.$ $=0.77]$, whereas GDPR and GMY were negatively correlated $\left[\mathrm{GDPR}=(-0.001 \times \mathrm{GMY})+2.589 ; \mathrm{R}^{2}=\right.$ 0.14]. A quadratic association $(P=0.08)$ was observed between GDPR and uterine diseases, but GDPR was not $(P \geq 0.11)$ associated with any other health event and removal from the herd within 60 DIM (Table 1 ). Although GDPR was not $(P \geq 0.35)$ associated with AMY14W and total milk yield within 14 wk postpartum (Table 1$)$, GMY was $(P<0.001)$ positively associated with AMY14W $[\mathrm{AMY} 14 \mathrm{~W}=34.1+(0.0031 \times$ GMY)] and total milk yield [total milk yield $=3,258.96$ $+(0.2420 \times$ GMY $)]$.

In Supplemental Table S1 (https://doi.org/10.3168/ jds.2020-18207), we depict the associations between cow class (embryo donor, embryo recipient, and AI) and GDPR, GCCR, GMY, and genomic merit for productive life and net merit. Embryo donors had $(P<0.01)$ greater GMY and genomic merit for productive life and net merit than cows not selected as embryo donors, whereas the latter had greater GDPR. Cows selected as embryo recipients had $(P \leq 0.05)$ reduced GMY and genomic merit for net merit than cows selected for AI, but they did not $(P \geq 0.35)$ differ regarding GDPR and GCCR.

\section{Rumination and Activity Peripartum}

During the prepartum period, GDPR was not $(P=$ 0.28 ) associated with daily rumination time, but there was $(P=0.04)$ a quadratic association between GMY 
and daily rumination time [rumination $=(-0.00004 \times$ $\left.\left.\mathrm{GMY}^{2}\right)+(0.0821 \times \mathrm{GMY})+425.2 ; \mathrm{R}^{2}=0.05\right]$. Similarly, during the postpartum period, GDPR was not $(P=0.21)$ associated with daily rumination time. The interaction between GMY and DIM tended $(P=0.10)$ to be associated with daily rumination time during the postpartum. This interaction was detected because GMY was not associated with rumination at 0 DIM; cows in the first and fourth quartiles had the lowest and greatest rumination from 1 to 28 DIM, respectively; and, the rumination of cows in the second and third quartiles only differ from 10 to 26 DIM. In addition, during the postpartum period, a quadratic association $(P<0.01)$ was observed between AMY14W and daily rumination time $\left[\right.$ rumination $=\left(-0.190 \times \mathrm{AMY}^{2} \mathrm{WW}^{2}\right)$ $\left.+(13.25 \times \mathrm{AMY} 14 \mathrm{~W})+246.0 ; \mathrm{R}^{2}=0.1167\right]$.

Genomic merit for DPR tended $(P=0.08)$ to be positively associated with activity prepartum (parameter estimate $=6.99 \pm 4.04)$, but it was not $(P=0.14)$ associated with activity postpartum. Genomic merit for milk yield was not associated with activity prepartum $(P=0.59)$ and postpartum $(P=0.48)$. No association $(P=0.22)$ was observed between AMY14W and activity postpartum.

\section{BCS and Concentrations of Hormones and Metabolites}

Genomic merit for DPR was not $(P \geq 0.49)$ associated with BCS prepartum and at $3 \pm 3$ DIM, but GDPR was $(P<0.01)$ positively associated with BCS at $63 \pm 3$ DIM (Table 1). In fact, a negative association $(P<0.01)$ was observed between GDPR and the probability of BCS change from 3 to $63 \pm 3$ DIM $\leq-0.75$ unit (Table 1). Genomic merit for milk yield was $(P=$ 0.03 ) positively associated with BCS prepartum (quartile $1=3.50 \pm 0.01$, quartile $2=3.48 \pm 0.01$, quartile $3=3.52 \pm 0.01$, quartile $4=3.53 \pm 0.01$ ), but it was not $(P \geq 0.19)$ associated with BCS at $3 \pm 3$ and $63 \pm$ 3 DIM. Milk yield up to 14 wk postpartum was $(P<$ $0.01)$ negatively associated with BCS at $63 \pm 3$ DIM.

Positive associations $(P<0.01)$ were observed between GDPR and IGF-1 concentration (Figure 1) and between GDPR and glucose concentration (Figure 2). Conversely, the associations between GDPR and NEFA concentration (Figure 3) and between GDPR and BHB concentration (Figure 4$)$ were $(P \leq 0.03)$ negative. Genomic merit for milk yield tended $(P=0.10)$ to be negatively associated with glucose concentration (Supplemental Figure S1A; https://doi.org/10.3168/ jds.2020-18207), was $(P<0.01)$ positively associated with NEFA concentration (Supplemental Figure S1B), and had $(P=0.02)$ a quadratic association with BHB
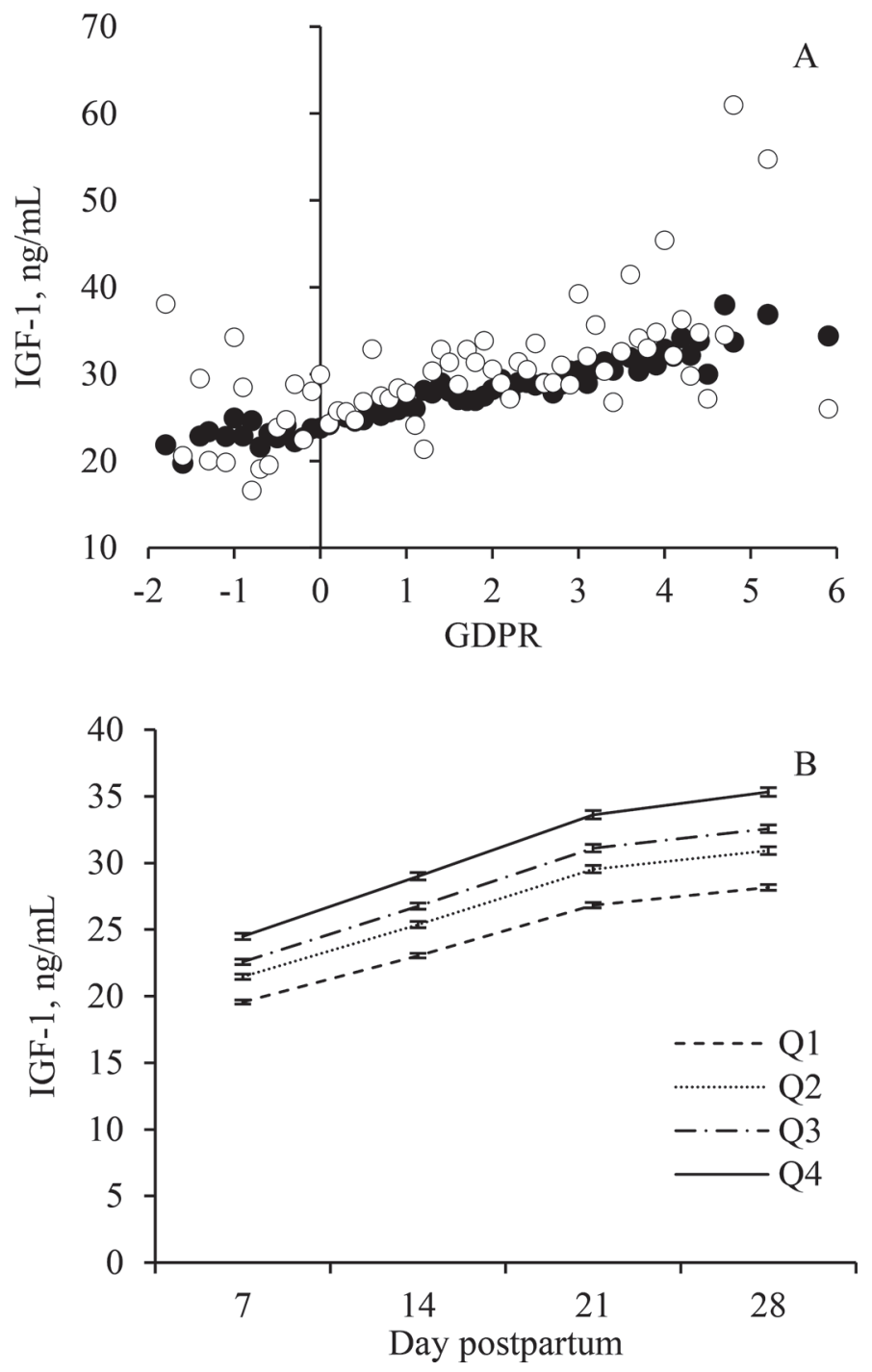

Figure 1. Association between genomic merit for daughter pregnancy rate (GDPR) and IGF-1 concentration from 7 to 28 DIM (A). Graphic representation of the association between GDPR quartile (Q1 $=-1.8$ to $0.8 ; \mathrm{Q} 2=0.9$ to $1.7 ; \mathrm{Q} 3=1.8$ to 2.5 ; and $\mathrm{Q} 4=2.6$ to 5.9 ) and IGF-1 concentration according to day postpartum (B). Effect: GDPR, $P<0.01$; day postpartum, $P<0.01$; and the interaction between GDPR and day postpartum, $P=0.83$. $\bullet$ Values generated based on the parameter estimates from the multivariable model. ORaw values. Error bars represent \pm SEM.

concentration (Supplemental Figure S1C). Average milk yield in the first $14 \mathrm{wk}$ postpartum was $(P<$ 0.01) negatively associated with IGF-1 (Supplemental Figure S2A; https://doi.org/10.3168/jds.2020-18207) and glucose (Supplemental Figure S2B) concentrations, whereas it was $(P<0.01)$ positively associated with BHB concentration (Supplemental Figure S2C). A tendency $(P=0.07)$ was observed for the AMY14W to have a quadratic association with NEFA concentration (Supplemental Figure S2D). 

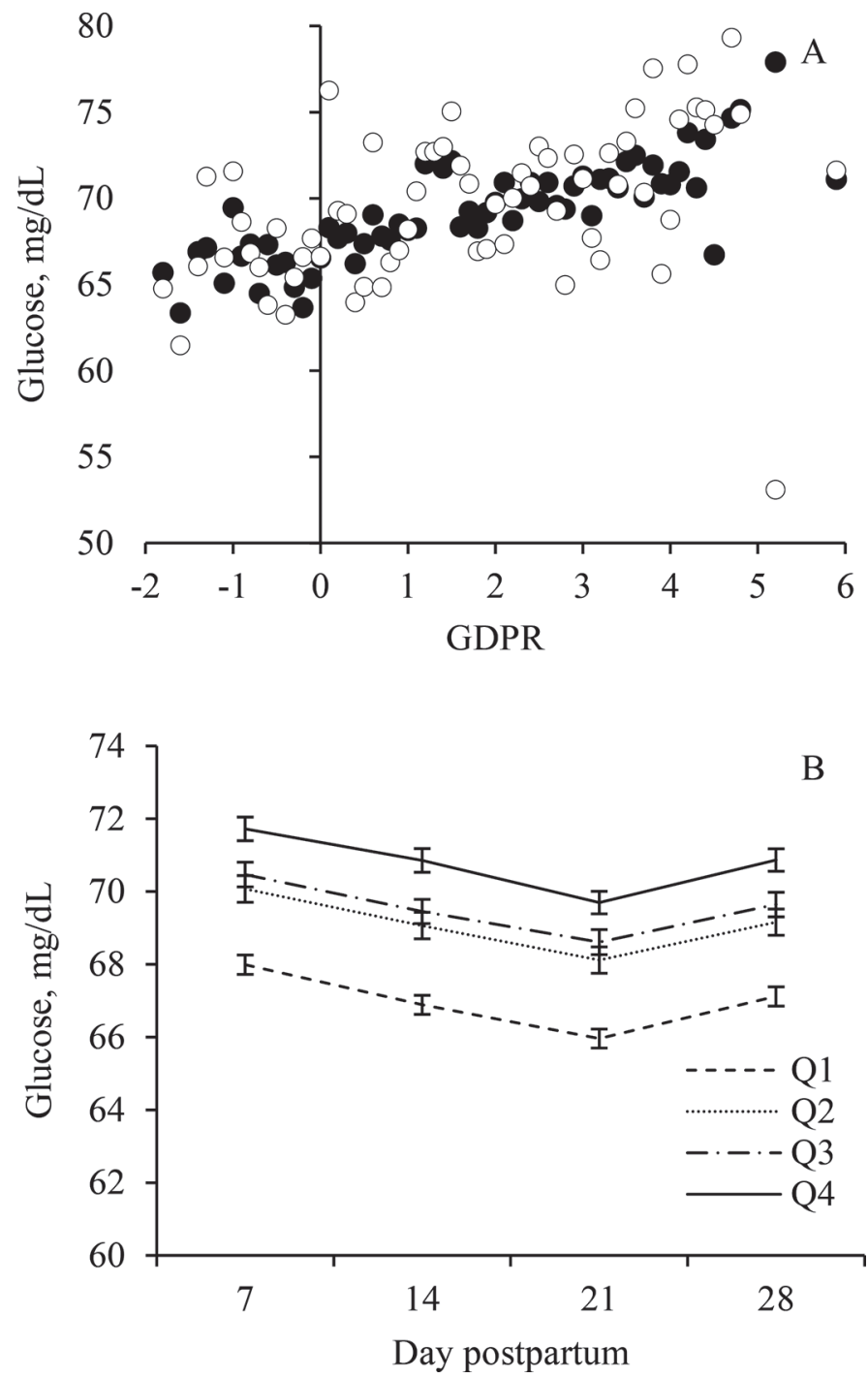

Figure 2. Association between genomic merit for daughter pregnancy rate (GDPR) and glucose concentration from 7 to 28 DIM (A). Graphic representation of the association between GDPR quartile (Q1 $=-1.8$ to $0.8 ; \mathrm{Q} 2=0.9$ to $1.7 ; \mathrm{Q} 3=1.8$ to 2.5 ; and $\mathrm{Q} 4=2.6$ to 5.9 ) and glucose concentration according to day postpartum (B). Effect: GDPR, $P<0.01$; day postpartum, $P=0.11$; and the interaction between GDPR and day postpartum, $P=0.95$. Values generated based on the parameter estimates from the multivariable model. ORaw values. Error bars represent \pm SEM.

\section{Estrus Characteristics}

Four hundred sixty-seven cows had at least one estrus recorded $\leq 62$ DIM ( 1 estrus event $=271 ; 2$ estrus events $=168 ; 3$ estrus events $=27 ; 4$ estrus events $=$ $1)$. The order of the estrus event (first to third events) was $(P<0.01)$ positively associated with the duration of estrus and the probability of heat index $\geq 86$ (Supplemental Figure S3; https://doi.org/10.3168/jds $.2020-18207)$. Genomic merit for DPR was $(P<0.01)$ positively associated with the hazard of estrus within
62 DIM [adjusted hazard ratio (AHR) and 95\% CI = $1.16(1.06,1.28)]$. The mean $( \pm \mathrm{SEM})$ and median intervals from calving to first estrus according to GDPR quartiles were quartile $1=52.7 \pm 0.9 \mathrm{~d}(<50 \%$ of cows were detected in estrus $\leq 62 \mathrm{DIM})$; quartile $2=51.5$ \pm 0.9 and $61 \mathrm{~d}$; quartile $3=48.0 \pm 1.0$ and $51 \mathrm{~d}$; and quartile $4=48.3 \pm 1.0$ and $51 \mathrm{~d}$ (Figure 5 ). A negative association $(P=0.04)$ was observed between GMY and hazard of estrus $[$ AHR $(95 \%$ CI $)=1.00(0.999,1.000)$; Supplemental Figure S4; https://doi.org/10.3168/jds .2020-18207].
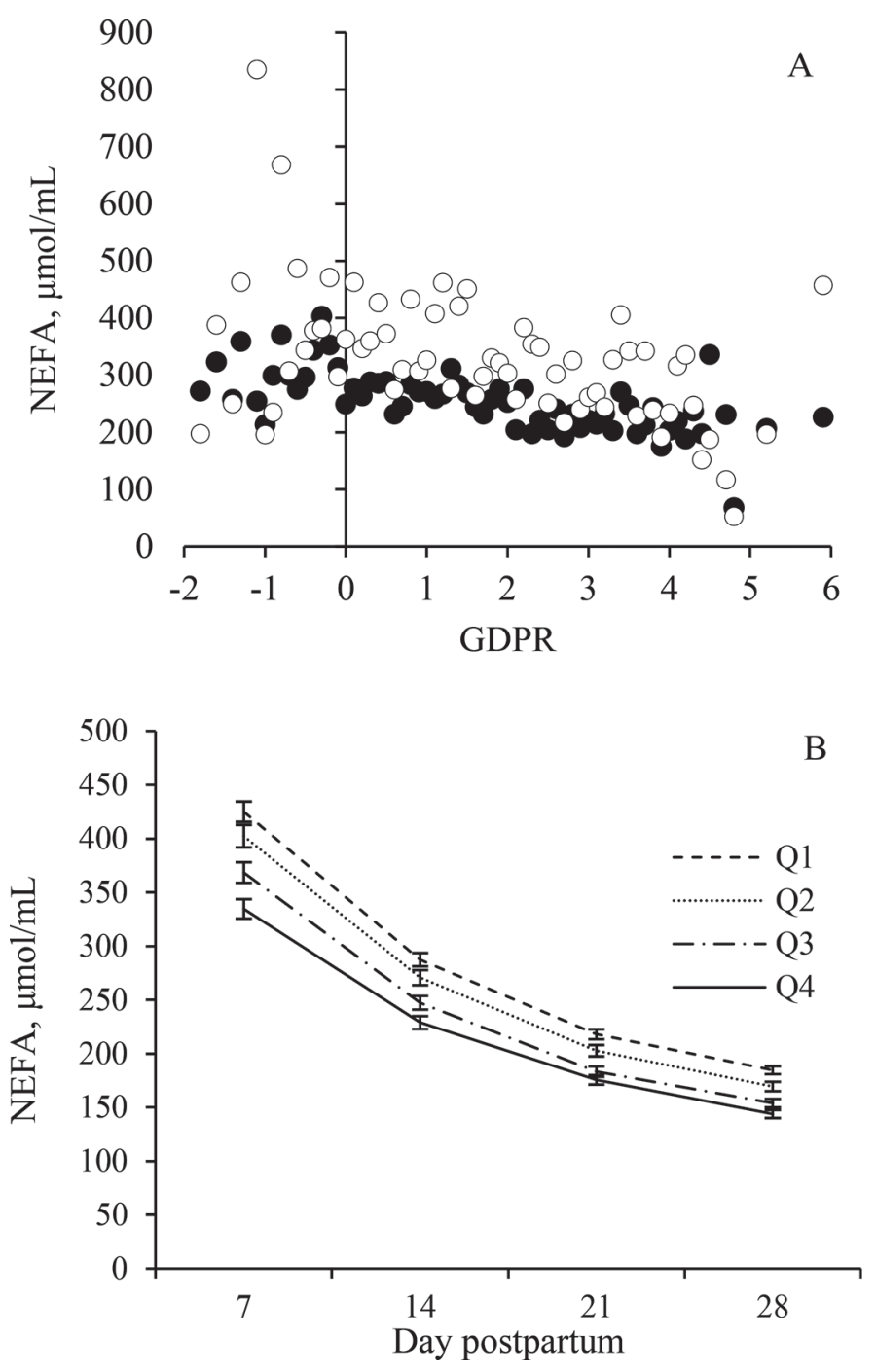

Figure 3. Association between genomic merit for daughter pregnancy rate (GDPR) and concentration of nonesterified fatty acids (NEFA) from 7 to 28 DIM (A). Graphic representation of the association between GDPR quartile $(\mathrm{Q} 1=-1.8$ to $0.8 ; \mathrm{Q} 2=0.9$ to $1.7 ; \mathrm{Q} 3$ $=1.8$ to 2.5 ; and $\mathrm{Q} 4=2.6$ to 5.9$)$ and NEFA concentration according to day postpartum (B). Effect: GDPR, $P<0.01$; day postpartum, $P$ $<0.01$; and the interaction between GDPR and day postpartum, $P=$ 0.65 . Values generated based on the parameter estimates from the multivariable model. ORaw values. Error bars represent \pm SEM. 
Genomic merit for DPR was positively associated with the number of estrus events up to 62 DIM $(P<$ $0.01)$ and was $(P=0.02)$ negatively associated with the interval between recorded estruses (Figure 6). The duration of estrus was $(P=0.02)$ positively associated with GDPR (Figure 7). Furthermore, the interaction between GMY and estrus event was $(P=0.01)$ associated with duration of estrus (Figure 7) because the duration of the first estrus was positively associated with GMY (13.8 to $15.3 \mathrm{~h}$ ), the duration of the second
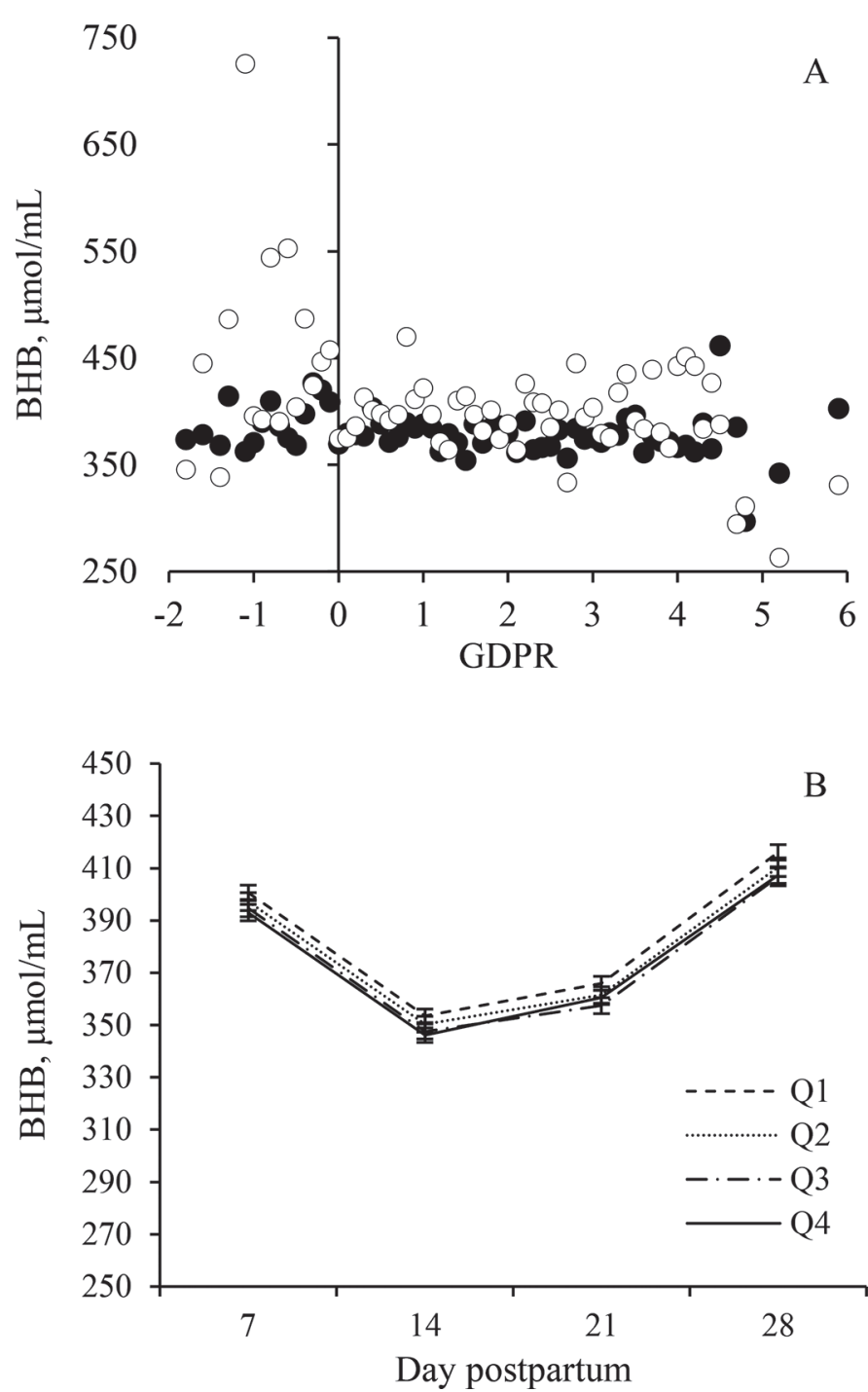

Figure 4. Association between genomic merit for daughter pregnancy rate (GDPR) and concentration of BHB from 7 to 28 DIM (A). Graphic representation of the association between GDPR quartile (Q1 $=-1.8$ to $0.8 ; \mathrm{Q} 2=0.9$ to $1.7 ; \mathrm{Q} 3=1.8$ to 2.5 ; and $\mathrm{Q} 4=2.6$ to 5.9) and BHB concentration according to day postpartum (B). Effect: GDPR, $P=0.03$; day postpartum, $P<0.01$; and the interaction between GDPR and day postpartum, $P=0.47$. $\bullet$ Values generated based on the parameter estimates from the multivariable model. ORaw values. Error bars represent \pm SEM

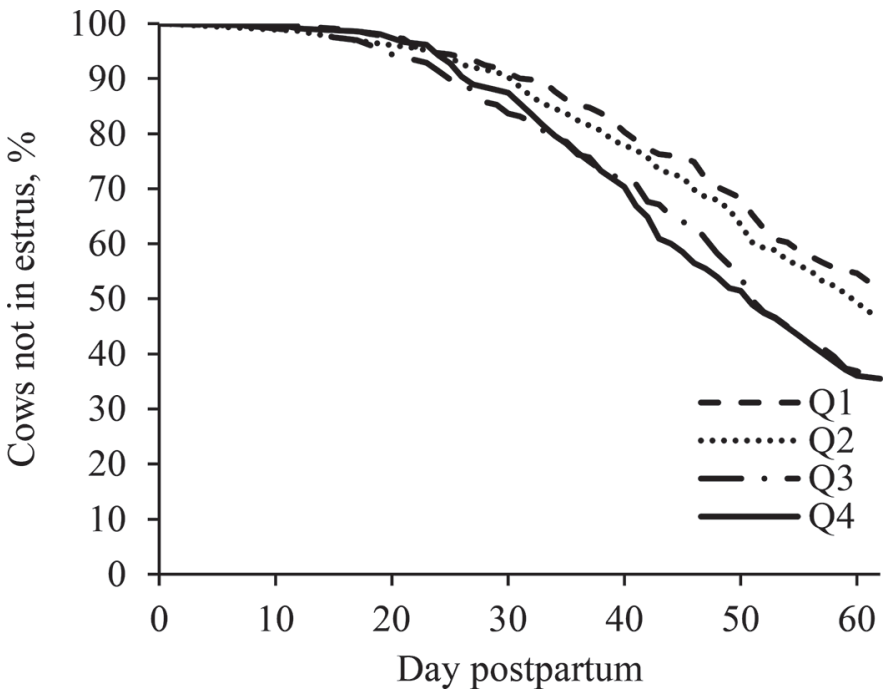

Figure 5. Associations between genomic merit for daughter pregnancy rate (GDPR; quartiles: Q1 $=-1.8$ to 0.8 ; $\mathrm{Q} 2=0.9$ to 1.7 ; $\mathrm{Q} 3=$ 1.8 to 2.5 ; and $\mathrm{Q} 4=2.6$ to 5.9 ) and rate at which cows were detected in estrus. Mean $( \pm \mathrm{SEM})$ and median intervals according to GDPR: $\mathrm{Q} 1=52.7 \pm 0.9(<50 \%$ of cows were detected in estrus $\leq 62$ DIM $)$; $\mathrm{Q} 2=51.5 \pm 0.9$ and $61 \mathrm{~d} ; \mathrm{Q} 3=48.0 \pm 1.0$ and $51 \mathrm{~d}$; and $\mathrm{Q} 4=48.3$ \pm 1.0 and $51 \mathrm{~d}$.

estrus postpartum remained relatively stable across GMY (15.5 to $16.3 \mathrm{~h}$ ), and the duration of the third estrus was negatively associated with GMY (17.4 to $13.7 \mathrm{~h})$.

Genomic merit for DPR was $(P<0.01)$ negatively associated with rumination nadir at estrus (Figure 8). Positive associations were observed between GDPR and probability of activity peak at estrus $\geq 86(P=$ 0.05; Figure 8) and between GDPR and probability of heat index at estrus $\geq 86(P<0.01$; Figure 8$)$. Average milk yield in the first $14 \mathrm{wk}$ postpartum was negatively associated with rumination nadir $(P=0.04)$ and had a quadratic association (estimates: linear $=0.1817 \pm$ 0.0738 , quadratic $=-0.0024 \pm 0.001)$ with the probability of activity peak $\geq 86(P \leq 0.02)$.

\section{Characteristics of Estrus Occurring Between 42 and 62 DIM}

Only 28 and 204 cows had an estrus recorded between calving and 20 DIM and between 21 and 41 DIM, respectively. Four hundred five cows were detected in estrus at least once between 42 and 62 DIM. Positive $(P<0.01)$ associations were observed between GDPR and the probability of estrus between 42 and 62 DIM and between GDPR and the number of estrus events recorded between 42 and 62 DIM (Table 2). Genomic merit for DPR was not associated with duration $(P$ $=0.11)$ and rumination nadir $(P=0.25)$ of the first 

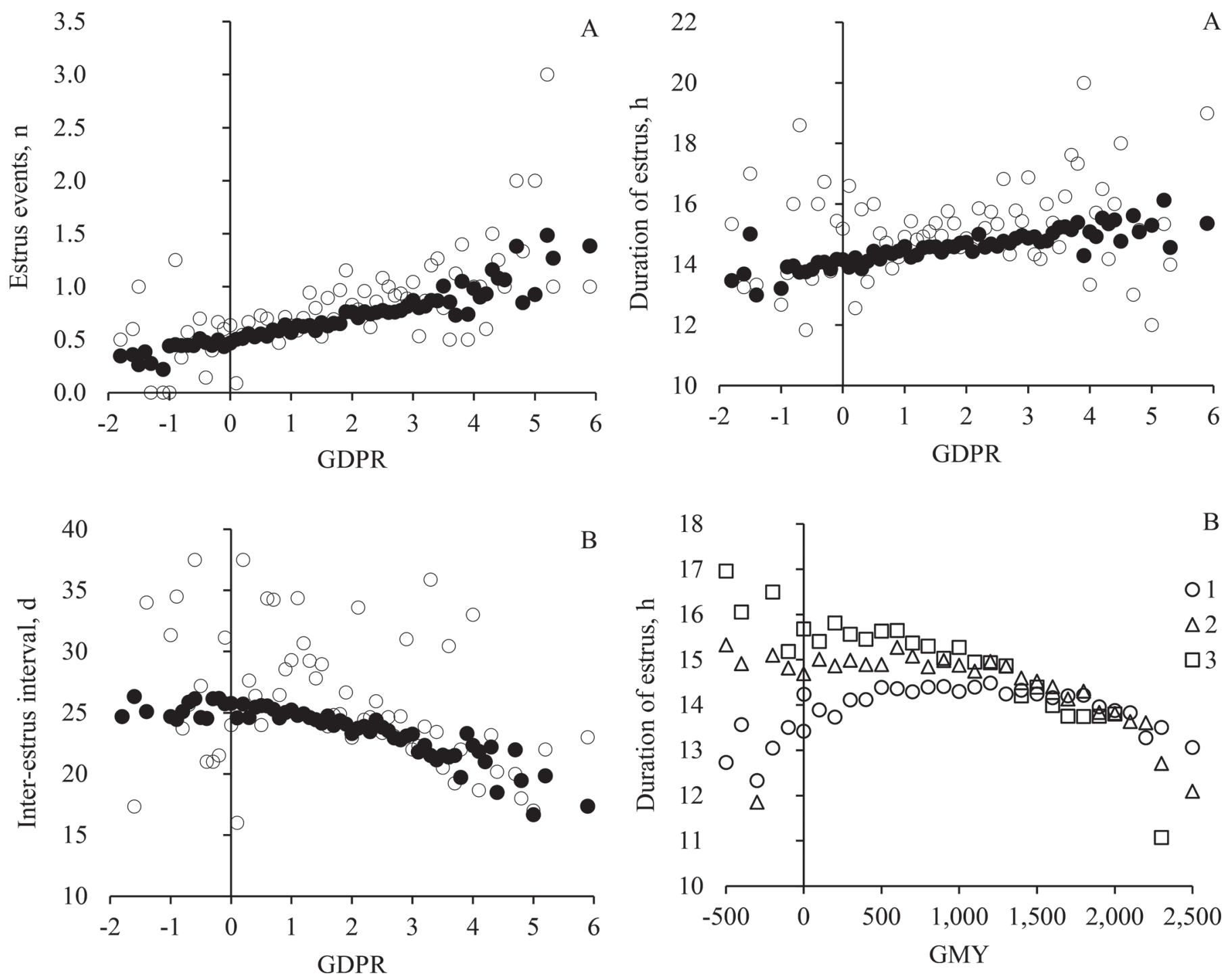

Figure 6. (A) Association between genomic merit for daughter pregnancy rate (GDPR) and number of recorded estrus events up to 62 DIM $(P<0.01)$, and $(B)$ interval between recorded estruses (linear, $P=0.09$; quadratic, $P=0.02)$. Values generated based on the parameter estimates from the multivariable model. ORaw values.

estrus recorded between 42 and 62 DIM and the probability of the first estrus recorded between 42 and 62 DIM to have activity peak $\geq 86(P=0.34)$. However, a positive association $(P=0.02)$ was observed between GDPR and the probability of the first estrus recorded between 42 and 62 DIM to have heat index $\geq 86$.

Genomic merit for milk yield tended $(P=0.09)$ to be negatively associated with the probability of activity peak $\geq 86$ (Supplemental Figure S5; https://doi.org/10 $.3168 /$ jds.2020-18207). Average milk yield up to $14 \mathrm{wk}$ postpartum was negatively $(P=0.01)$ associated with rumination nadir (Supplemental Figure S6A; https:/ /doi.org/10.3168/jds.2020-18207) and positively $(P=$

Figure 7. (A) Association between duration of estrus and genomic merit for daughter pregnancy rate (GDPR, $P=0.02$ ), and (B) genomic merit for milk yield (GMY; GMY, $P=0.91$; estrus event, $P$ $<0.01$; and GMY $\times$ estrus event, $P=0.01$ ) and duration of estrus. - Values generated based on the parameter estimates from the multivariable model. $\bigcirc$ Raw values. $\bigcirc$ First, $\Delta$ second, and $\square$ third estrus postpartum.

$0.05)$ associated with the probability of activity peak $\geq 86$ (Supplemental Figure S6B; https://doi.org/10 $.3168 /$ jds.2020-18207).

\section{Reproductive Performance}

Reproductive performance data are reported in Table 3. Genomic merit for DPR was $(P<0.01)$ associated with hazard of first service and a tendency $(P=0.10)$ was observed for a quadratic association between GDPR and DIM at first postpartum service. Genomic merit for DPR was $(P<0.01)$ negatively associated with the 

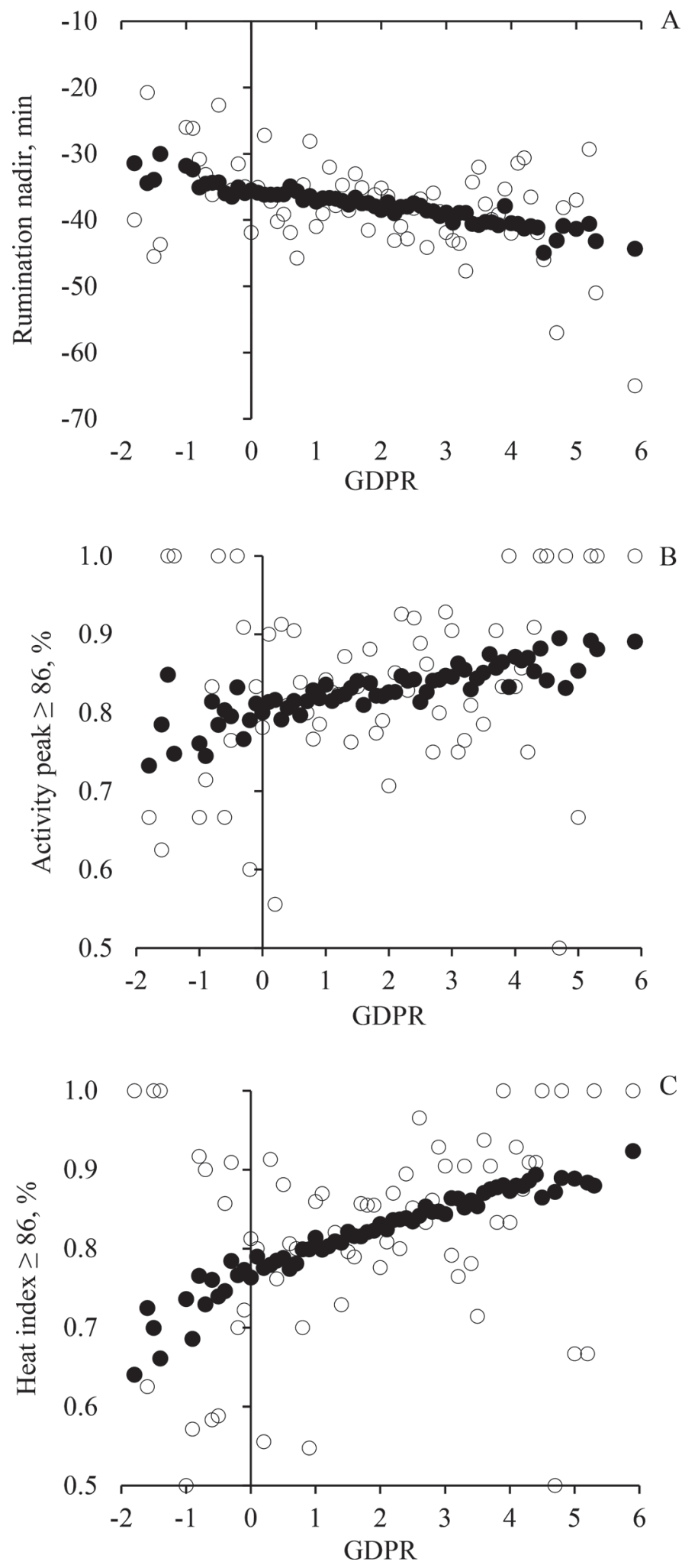

Figure 8. Association between genomic merit for daughter pregnancy rate $($ GDPR $)$ and rumination nadir at estrus $(\mathrm{A} ; P<0.01)$, probability of activity peak $\geq 86$ (B; $P<0.01$ ), and probability of heat index $\geq 86(\mathrm{C} ; P<0.01)$. Values generated based on the parameter estimates from the multivariable model. ORaw values. probability of first service at fixed time. Conversely, GDPR was not $(P \geq 0.44)$ associated with pregnancy and pregnancy loss after the first service.

Average milk yield in the first 14 wk postpartum was $(P<0.01)$ positively associated with pregnancy at $38 \pm 3$ and $87 \pm 3 \mathrm{~d}$ after first service (Supplemental Figure S7; https://doi.org/10.3168/jds.2020-18207). A tendency $(P=0.06)$ was observed for AMY14W to have a quadratic association with pregnancy loss from 38 to $87 \pm 3$ d after first service (Supplemental Figure S7).

Genomic merit for DPR was $(P \leq 0.01)$ positively associated with the hazard of second service and was negatively associated with the interval between the first and second services. A quadratic association $(P$ $=0.02$ ) was observed between GDPR and probability of second service at fixed time. Although GDPR was not $(P \geq 0.18)$ associated with pregnancy at 38 and 87 $\pm 3 \mathrm{~d}$ after second service, a tendency $(P=0.06)$ was observed for GDPR to be negatively associated with the probability of pregnancy loss between 38 and $87 \pm$ $3 \mathrm{~d}$ after the second service.

Genomic merit for milk yield was $(P=0.05)$ and tended to be $(P=0.07)$ negatively associated with the interval between first and second services and probability of second service at fixed time (Supplemental Figure S8; https://doi.org/10.3168/jds.2020-18207). A quadratic association was observed between GMY and pregnancy $38 \pm 3(P=0.01)$ and $87 \pm 3(P=0.06)$ $\mathrm{d}$ after second service (Supplemental Figure S9; https: //doi.org/10.3168/jds.2020-18207). Genomic merit for milk yield was not $(P=0.70)$ associated with pregnancy loss from 38 to $87 \pm 3 \mathrm{~d}$ after the second service.

Finally, GDPR was $(P<0.01)$ positively associated with the hazard of pregnancy $(\mathrm{AHR}=1.11,95 \% \mathrm{CI}=$ $1.03,1.19)$. The mean $( \pm \mathrm{SEM})$ and median intervals from calving to pregnancy were quartile $1=118.5 \pm$ 2.3 and $131 \mathrm{~d}$, quartile $2=117.9 \pm 2.3$ and $128 \mathrm{~d}$, quartile $3=115.3 \pm 2.5$ and $118 \mathrm{~d}$, quartile $4=113.1$ \pm 2.4 and $117 \mathrm{~d}$. Average milk yield in the first $14 \mathrm{wk}$ postpartum was $(P<0.01)$ positively associated with hazard of pregnancy $(\mathrm{AHR}=1.04,95 \% \mathrm{CI}=1.02$, 1.06).

\section{DISCUSSION}

The positive correlation between GDPR and GCCR and the negative correlation between GDPR and GMY observed in the current study were expected. These patterns are observed in the US bull and cow populations (https://www.uscdcb.com/what-we-can-do-for-you/ evaluation-results/). Despite the negative correlation between GDPR and GMY, GDPR was not associated with AMY14W and total milk yield in the first $14 \mathrm{wk}$ 
Table 2. Association between genomic merit for daughter pregnancy rate (DPR) and characteristics of the first estrus occurring between 42 and 62 DIM

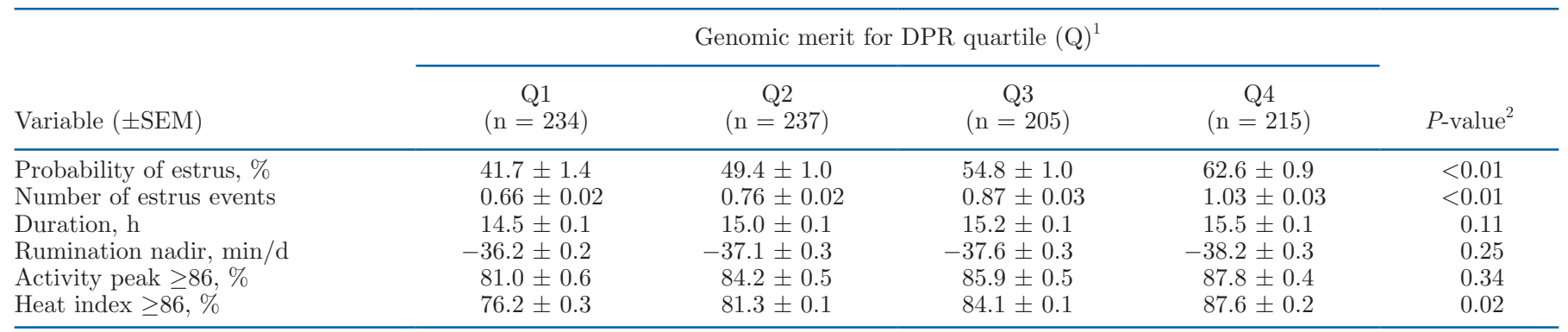

${ }^{1}$ Genomic merit for DPR: Q1 $=-1.8$ to 0.8 ; Q2 $=0.9$ to 1.7 ; Q3 = 1.8 to 2.5 ; Q4 $=2.6$ to 5.9 .

${ }^{2}$ Referent to the results of the multivariable analyses in which genomic merit for DPR was used as a continuous variable and tested for its linear and quadratic associations with the outcomes of interest.

postpartum. This created the opportunity to evaluate the associations between a fertility trait commonly used in genetic selection programs of dairy cattle and peripartum metabolic status, return to estrus cyclicity, and estrus characteristics without the confounding effect of differing phenotypic milk yield.

The shorter interval from calving to first postpartum estrus associated with greater GDPR may be a consequence of the positive associations between GDPR and concentrations of IGF-1 and BCS. A positive genetic correlation between BCS and resumption of cyclicity (Carthy et al., 2016) and a negative genetic correlation between BCS and interval from calving to first service (Berry et al., 2003) have been observed in Irish cattle.
Cummins et al. (2012b) and Moore et al. (2014a) demonstrated that cows that had positive EBV for CIN (fert-) had reduced IGF-1 concentration postpartum compared with cows that had negative EBV for CIN (fert+). This difference in IGF-1 concentration between fert- and fert+ cows may have been associated with different hepatic expression of mRNA for IGF binding proteins $(2,4,5$, and 6$)$ because no differences in hepatic expression for growth hormone receptor $1 \mathrm{~A}$ and IGF-1 were observed (Cummins et al., 2012b). Another possible explanation for the differences in IGF1 between fert- and fert+ cows was the differences in DMI and energy balance observed by Moore et al. (2014a). Beam and Butler (1998) demonstrated that

Table 3. Association between genomic merit for daughter pregnancy rate (DPR) and reproductive performance of primiparous Holstein cows

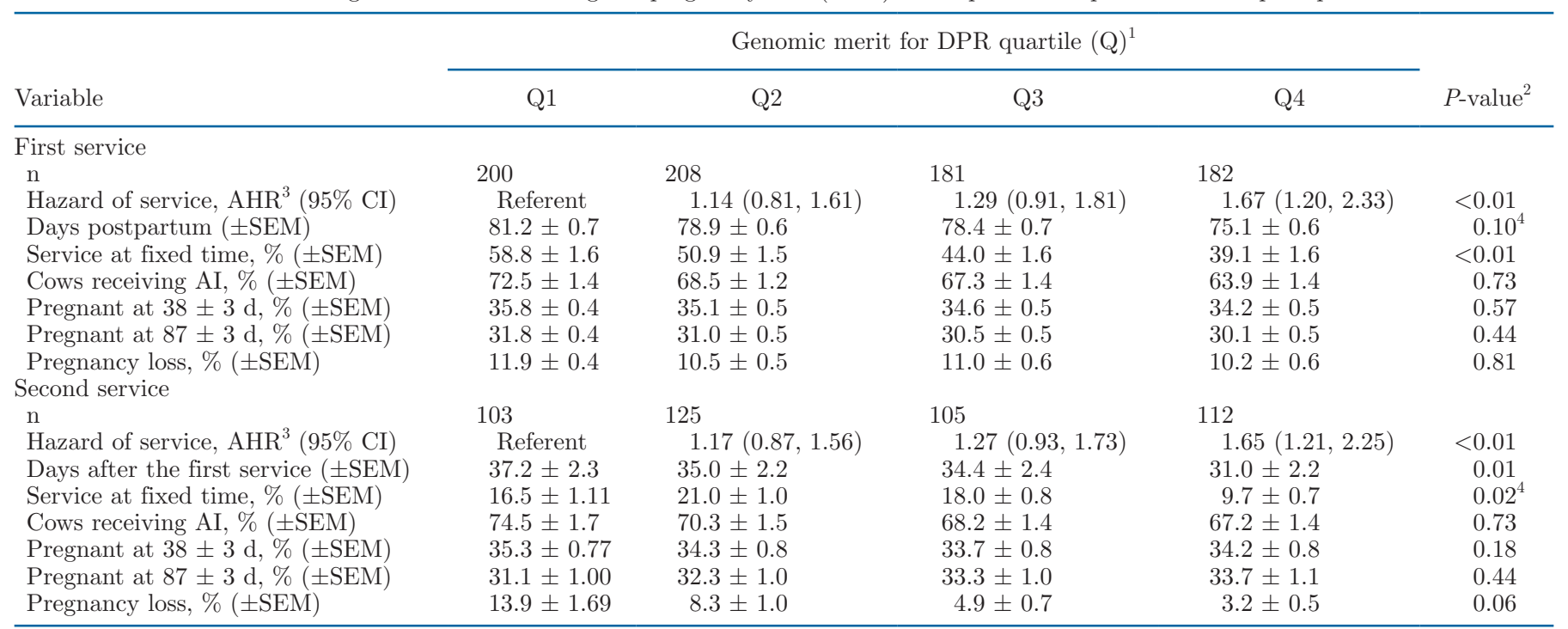

${ }^{1}$ Genomic merit for DPR: Q1 $=-1.8$ to $0.8 ; \mathrm{Q} 2=0.9$ to 1.7 ; Q3 = 1.8 to 2.5 ; Q4 = 2.6 to 5.9 .

${ }^{2}$ Referent to the results of the multivariable analyses in which genomic merit for DPR was used as a continuous variable and tested for its linear and quadratic associations with the outcomes of interest.

${ }^{3} \mathrm{AHR}=$ adjusted hazard ratio.

${ }^{4}$ Quadratic association. 
cows that ovulated the follicle of the first postpartum follicular wave had greater IGF-1 concentrations and less intense negative energy balance postpartum than cows that did not ovulate. Together, these data suggest that selection for GDPR may hasten return to ovarian cycles because of less dramatic negative energy balance and greater IGF-1 concentration during the postpartum period.

Dry matter intake was not measured in the current study because it was conducted in a commercial herd. We did not detect, however, an association between GDPR and rumination time during the peripartum period. Although the correlation between rumination time and DMI within a 2 -h period is negative, over time, greater rumination follows an increase in DMI when dietary factors remain constant (Schirmann et al., 2013). From the current study, we cannot conclude, however, that cows with differing GDPR do not differ in DMI during the peripartum period. Coyral-Castel et al. (2013) classified cows as fert+ and fert- based on haplotypes in the QTL affecting female fertility on the BTA3. Those cows classified as fert+ had greater DMI at wk 1, 2, and 4 postpartum and spent more time at the feeder from 1 to 7 wk postpartum, but this may have been confounded by their greater milk yield from 2 to 7 wk postpartum. In addition, fert+ cows had greater live BW from 1 to 7 wk postpartum and no differences in energy balance from 1 to 7 wk postpartum were observed. Conversely, Moore et al. (2014a) demonstrated that DMI postpartum, energy balance, and IGF-1 concentration postpartum were greater for cows on the top $20 \%$ for CIN than cows on the bottom $5 \%$ for CIN. Additional studies are necessary to elucidate the associations between genetic merit for fertility traits and peripartum energy balance.

The positive association between GDPR and glucose concentration and the negative correlations between GDPR and BHB and NEFA concentrations in the first 28 DIM support the conclusion that selection for GDPR positively affected the metabolic status early postpartum. In the current study, we did not measure DMI and milk composition, which does not allow us to conclude whether the association between GDPR and glucose and NEFA concentrations is confounded by differences in intake or output of energy (or both). The negative associations between NEFA concentrations postpartum and reproductive performance have been reported previously (Ospina et al., 2010; Garverick et al., 2013). Researchers from the United Kingdom demonstrated that cows diagnosed with subclinical ketosis within 21 DIM had reduced duration of estrus and activity peak at estrus compared with cows that were healthy up to the first AI (Rutherford et al., 2016). In addition, Garverick et al. (2013) demonstrated that cows diagnosed pregnant to the first postpartum AI had greater concentrations of glucose peripartum. Moore et al. (2017) evaluated metabolite, fatty acid, and AA concentrations of serum and follicular fluid of cows on the top $20 \%$ in genetic merit for CIN (fert+) and on the bottom $5 \%$ in genetic merit for CIN (fert-). Cows classified as fert+ had greater concentrations of total PUFA and n-6 PUFA, whereas fert- cows had a greater concentration of SFA (Moore et al., 2017). These findings suggest that additional studies are necessary to evaluate the differences in fatty acid profile according to GDPR and how it affects reproductive success of lactating dairy cows.

Genomic merit for milk yield was positively associated with prepartum BCS, but during the postpartum, it was negatively associated with IGF-1 and positively associated with NEFA concentrations. Snijders et al. (2001) demonstrated that cows with greater pedigreebased milk yield estimates had reduced IGF-1 and glucose concentrations postpartum, but no differences in NEFA concentrations were observed. Weber et al. (2007) demonstrated that cows from an unselected lineage had greater IGF-1 and reduced NEFA concentration during the postpartum period compared with cows genetically selected for milk yield. The reduced IGF-1 and greater NEFA concentrations during the postpartum in cows highly selected for milk yield are hypothesized to be a consequence of the downregulation of hepatic growth hormone receptor 1A expression and more intense negative energy balance postpartum in highly selected cows compared with cows of lower genetic merit for milk yield (Lucy et al., 2009).

The positive association between GDPR and the hazard of estrus demonstrates that the postpartum metabolic status associated with GDPR may have played a role in earlier resumption of ovarian cycles. Rojas Canadas et al. (2020) demonstrated that cows with lower genetic EBV for CIN were more likely to have a corpus luteum present at 3 wk postpartum compared with cows with greater genetic EBV for CIN. In the current study, we did not confirm by ultrasound or progesterone concentration that cows that displayed estrus had in fact ovulated. The automated estrus-detection device used in the current study has sensitivity and specificity $\geq 90 \%$ to detect ovulation compared with ultrasonography (Valenza et al., 2012; Dolecheck et al., 2015). It is noteworthy that cows on the bottom $5 \%$ for CIN (fert-) were more likely to fail to demonstrate estrus before ovulation and were more likely to fail to ovulate after expressing estrus compared with cows on the top 20\% for CIN (fert+; Cummins et al., 2012a). Thus, the positive association between GDPR and hazard of first estrus suggests that selection for GDPR may in fact hasten return to ovarian cycles and ser- 
vice. This is an important finding of the current study because earlier resumption of ovarian cycles leads to greater pregnancy rate (Chebel and Santos, 2010). In the current study, GDPR was positively associated with the number of estrus events within 62 DIM and was negatively associated with the interval between estrus events. The greater number of estrus events within 62 DIM in cows with greater GDPR may be a consequence of the hastened resumption of ovarian cycles and the shorter interval between estrus events. Cummins et al. (2012a) demonstrated that the interovulatory interval was approximately $4 \mathrm{~d}$ shorter for fert+ cows (top $20 \%$ for CIN) compared with fert- cows (bottom $5 \%$ for CIN). This may be explained in part by the fact that fert + cows had earlier luteolysis and shorter interval from luteolysis to ovulation compared with fert- cows (Cummins et al., 2012a). In the current study, the difference in interestrus interval between the extremes in GDPR was as high as $9.6 \mathrm{~d}$ and it was $3.4 \mathrm{~d}$ between cows in the bottom and top quartile for GDPR. Other studies should be conducted to elucidate whether growth rate and maturation of follicles of cows differing in GDPR could explain the differences in interestrus interval observed in the current study.

Genomic merit for DPR was associated with longer duration and more intense signs of estrus (reduced rumination nadir and greater probability of activity peak/heat index $\geq 86$ ). In addition, during the interval between 42 and 62 DIM, GDPR was positively associated with the probability of estrus, number of estrus events, and probability of heat index $\geq 86$. These characteristics are in line with the hypothesis that GDPR is associated with more intense estrus. The estrus characteristics monitored in the current study are indirect signs of estrus, but standing to be mounted is a behavior positively associated with duration of estrus and peak of activity measured by automated estrusdetection devices (Silper et al., 2015). Cummins et al. (2012a) demonstrated that cows on the top $20 \%$ for CIN had a longer duration of estrus and greater peak activity than cows on the bottom $5 \%$ for CIN. Although in the current study we did not evaluate reproductive hormones and ovarian dynamics, in a previous study using the same animals at approximately 13 mo of age, we demonstrated that GDPR was positively associated with characteristics of $\mathrm{PGF}_{2 \alpha}$-induced estrus, estradiol concentration within $24 \mathrm{~h}$ of estrus, and diameter of the ovulatory follicle (Veronese et al., 2019a,b). The association between fertility traits and follicle development and estradiol concentration is not completely understood. Moore et al. (2014b) demonstrated that cows on the top $20 \%$ in genetic merit for CIN had larger dominant follicles and greater estradiol concentrations around estrus than those on the bottom $5 \%$ for CIN.
Cummins et al. (2012a), however, did not detect differences in the pattern of estradiol concentration around the time of estrus between cows on the bottom $5 \%$ and on the top $20 \%$ for CIN, despite the latter having larger ovulatory follicles. These findings raise the question of whether selection for fertility traits alters steroidogenesis by the ovaries or the responsiveness of the hypothalamus-pituitary axis to these steroids (or both).

In the current study, GMY was negatively associated with the duration of the third estrus event recorded postpartum and the probability of activity peak $\geq 86$ between 42 and 62 DIM. Consequently, GMY was negatively associated with the hazard of estrus. High producing dairy cows have reduced estradiol concentration at estrus, decreased duration and intensity of estrus, fewer mounts per estrus, and stand to be mounted fewer seconds per estrus than low producing cows (Lyimo et al., 2000; Lopez et al., 2004; Aungier et al., 2015). It is noteworthy that, in the current study, we controlled for milk yield when investigating the associations between GDPR/GMY and characteristics of estrus and, in fact, AMY14W was positively associated with a few estrus characteristics. This leads us to speculate that the association between GMY and estrus characteristics may result from genetic differences and not simply differences in milk yield. Our findings lead to the conclusion that the selection of dairy cattle should continue to strive for greater GMY while closely controlling for GDPR to prevent negative consequences to expression of estrus.

An expected consequence of more intense estrus is greater hazard of service. In fact, we demonstrated that GDPR was positively associated with the hazards of first and second services. The interval from calving to first service and the interval between first and second services were $6 \mathrm{~d}$ shorter for cows in the top quartile for GDPR compared with cows in the bottom quartile for GDPR. These findings demonstrate that selection for GDPR affects reproductive performance particularly by expediting the service of nonpregnant cows. In the current study, GDPR was not associated with pregnancy after the first and second services. Although GDPR was negatively associated with pregnancy loss from 38 to $87 \pm 3 \mathrm{~d}$ after the second service, the number of cows pregnant at $38 \pm 3 \mathrm{~d}$ after the second service was small $(n=157)$. A recent study demonstrated that duration of estrus was positively associated with the likelihood of pregnancy (Burnett et al., 2017). Thus, we expected that the GDPR-associated improvements in estrus characteristics would result in greater $\mathrm{P} /$ Serv. Veronese et al. (2019a), using the same animals, demonstrated that GDPR was positively associated with estrus characteristics and P/Serv of heifers. Cows on the top $20 \%$ 
for CIN had shorter days open and increased $\mathrm{P} /$ Serv in the first 2 services postpartum compared with cows on the bottom 5\% for CIN (Cummins et al., 2012c). The reduced $\mathrm{P} /$ Serv for less fertile cows may not be explained by differences in oocyte quality and embryo development up to d 7 after ovulation (Moore et al., 2019). We recently demonstrated that GDPR was positively associated with the concentration of pregnancy specific protein B from 19 to $35 \mathrm{~d}$ after service in heifers diagnosed pregnant at $38 \pm 3 \mathrm{~d}$ after service, the same animals used in the current study (Veronese et al., 2019b). In a recent epidemiological study, Lima et al. (2020) demonstrated that GDPR was positively associated with pregnancy per AI, independent of whether the cows were inseminated at fixed time or at detected estrus. Further studies are needed to more clearly elucidate the association between fertility traits and early development of embryos and maternal recognition of pregnancy. Despite the lack of association between GDPR and P/Serv, GDPR was positively associated with the hazard of pregnancy, resulting in shorter interval from calving to the establishment of pregnancy. This finding reinforces the importance of selecting dairy cattle for fertility traits that improve estrus characteristics.

\section{CONCLUSIONS}

We conclude from this study that selection for GDPR has the potential to improve the hormonal and metabolic recovery of cows postpartum, which may lead to earlier resumption of estrus cycles. In addition, selection of cows for GDPR may improve detection of estrus in commercial herds because this reproductive trait was associated with longer duration of estrus and more intense signs of estrus (rumination nadir, activity peak, and heat index). Surprisingly, the data from this study suggest that selection for GDPR improves reproductive performance mainly because of the earlier resumption of estrus cycles postpartum and characteristics of estrus instead of improvements in $\mathrm{P} /$ Serv.

\section{ACKNOWLEDGMENTS}

The authors thank the owners and staff of North Florida Holsteins dairy (Bell, FL) for their support and collaboration. The authors have not stated any conflicts of interest.

\section{REFERENCES}

AIPL. (Animal Improvement Programs Laboratory, ARS-USDA). 2013. Daughter pregnancy rate evaluation of cow fertility. https:// aipl.arsusda.gov/reference/fertility/DPR_rpt.htm.
Aungier, S. P. M., J. F. Roche, P. Duffy, S. Scully, and M. A. Crowe. 2015. The relationship between activity clusters detected by an automatic activity monitor and endocrine changes during the periestrous period in lactating dairy cows. J. Dairy Sci. 98:1666-1684. https://doi.org/10.3168/jds.2013-7405.

Beam, S. W., and W. R. Butler. 1998. Energy balance, metabolic hormones, and early postpartum follicular development in dairy cows fed prilled lipids. J. Dairy Sci. 81:121-131. https://doi.org/ 10.3168/jds.S0022-0302(98)75559-6.

Berry, D. P., F. Buckley, P. Dillon, R. D. Evans, M. Rath, and R. F. Veerkamp. 2003. Genetic relationships among body condition score, body weight, milk yield, and fertility in dairy cows. J. Dairy Sci. 86:2193-2204. https://doi.org/10.3168/jds.S0022 -0302(03)73809-0.

Britt, J. H., R. G. Scott, J. D. Armstrong, and M. D. Whitacre. 1986. Determinants of estrous behavior in lactating Holstein cows. J. Dairy Sci. 69:2195-2202. https://doi.org/10.3168/jds.S0022 $-0302(86) 80653-1$.

Burnett, T. A., A. M. L. Madureira, B. F. Silper, A. C. C. Fernandes, and R. L. A. Cerri. 2017. Integrating an automated activity monitor into an artificial insemination program and the associated risk factors affecting reproductive performance of dairy cows. J. Dairy Sci. 100:5005-5018. https://doi.org/10.3168/jds.2016-12246.

Carthy, T. R., D. P. Ryan, A. M. Fitzgerald, R. D. Evans, and D. P. Berry. 2016. Genetic relationships between detailed reproductive traits and performance traits in Holstein-Friesian dairy cattle. J. Dairy Sci. 99:1286-1297. https://doi.org/10.3168/jds.2015-9825.

Chebel, R. C., and J. E. Santos. 2010. Effect of inseminating cows in estrus following a presynchronization protocol on reproductive and lactation performances. J. Dairy Sci. 93:4632-4643. https:// doi.org/10.3168/jds.2010-3179.

Chenault, J. R., J. F. McAllister, S. T. Chester Jr., K. J. Dame, F. M. Kausche, and E. J. Robb. 2004. Efficacy of ceftiofur hydrochloride sterile suspension administered parenterally for the treatment of acute postpartum metritis in dairy cows. J. Am. Vet. Med. Assoc. 224:1634-1639. https://doi.org/10.2460/javma.2004.224.1634.

Coyral-Castel, S., P. Faverdin, C. Ramé, S. Fréret, D. Guillaume, S. Fritz, and J. Dupont. 2013. Significant differences in fertility between dairy cows selected for one QTL located on bovine chromosome 3 are not attributable to energy balance, although eating behaviour is affected. Animal 7:610-617. https://doi.org/10.1017/ S1751731112002133.

Cummins, S. B., P. Lonergan, A. C. Evans, D. P. Berry, R. D. Evans, and S. T. Butler. 2012c. Genetic merit for fertility traits in Holstein cows: I. Production characteristics and reproductive efficiency in a pasture-based system. J. Dairy Sci. 95:1310-1322. https://doi.org/10.3168/jds.2011-4742.

Cummins, S. B., P. Lonergan, A. C. Evans, and S. T. Butler. 2012a. Genetic merit for fertility traits in Holstein cows: II. Ovarian follicular and corpus luteum dynamics, reproductive hormones, and estrus behavior. J. Dairy Sci. 95:3698-3710. https://doi.org/10 $.3168 /$ jds.2011-4976.

Cummins, S. B., S. M. Waters, A. C. Evans, P. Lonergan, and S. T. Butler. 2012b. Genetic merit for fertility traits in Holstein cows: III. Hepatic expression of somatotropic axis genes during pregnancy and lactation. J. Dairy Sci. 95:3711-3721. https://doi.org/ 10.3168/jds.2011-4977.

Dairy Records Management Systems. 2016. Raleigh, NC. https://www .drms.org/.

De Rensis, F., I. Garcia-Ispierto, and F. López-Gatius. 2015. Seasonal heat stress: Clinical implications and hormone treatments for the fertility of dairy cows. Theriogenology 84:659-666. https://doi .org/10.1016/j.theriogenology.2015.04.021.

Dolecheck, K. A., W. J. Silvia, G. Heersche Jr., Y. M. Chang, D. L. Ray, A. E. Stone, B. A. Wadsworth, and J. M. Bewley. 2015. Behavioral and physiological changes around estrus events identified using multiple automated monitoring technologies. J. Dairy Sci. 98:8723-8731. https://doi.org/10.3168/jds.2015-9645.

Duffield, T. F., K. D. Lissemore, B. W. McBride, and K. E. Leslie. 2009. Impact of hyperketonemia in early lactation dairy cows on 
health and production. J. Dairy Sci. 92:571-580. https://doi.org/ 10.3168/jds.2008-1507.

Ferguson, J. D., D. T. Galligan, and N. Thomsen. 1994. Principal descriptors of body condition score in Holstein cows. J. Dairy Sci. 77:2695-2703. https://doi.org/10.3168/jds.S0022-0302(94)77212 $-\mathrm{X}$.

García-Ruiz, A., J. B. Cole, M. Paul, G. R. Wiggans, F. J. Ruiz-López, and P. Curtis. 2016. Changes in genetic selection differentials and generation intervals in US Holstein dairy cattle as a result of genomic selection. Proc. Natl. Acad. Sci. USA 113:E3995-E4004. https://doi.org/10.1073/pnas.1611570113.

Garverick, H. A., M. N. Harris, R. Vogel-Bluel, J. D. Sampson, J. Bader, W. R. Lamberson, J. N. Spain, M. C. Lucy, and R. S. Youngquist. 2013. Concentrations of nonesterified fatty acids and glucose in blood of periparturient dairy cows are indicative of pregnancy success at first insemination. J. Dairy Sci. 96:181-188. https://doi.org/10.3168/jds.2012-5619.

Kelton, D. F., K. D. Lissemore, and R. E. Martin. 1998. Recommendations for recording and calculating the incidence of selected clinical diseases of dairy cattle. J. Dairy Sci. 81:2502-2509. https://doi .org/10.3168/jds.S0022-0302(98)70142-0.

Lima, F. S., F. T. Silvestre, F. Peñagaricano, and W. W. Thatcher. 2020. Early genomic prediction of daughter pregnancy rate is associated with improved reproductive performance in Holstein dairy cows. J. Dairy Sci. 103:3312-3324. https://doi.org/10.3168/jds .2019-17488.

Lopez, H., L. D. Satter, and M. C. Wiltbank. 2004. Relationship between level of milk production and estrous behavior of lactating dairy cows. Anim. Reprod. Sci. 81:209-223. https://doi.org/10 .1016/j.anireprosci.2003.10.009.

Lucy, M. C. 2007. Fertility in high-producing dairy cows: Reasons for decline and corrective strategies for sustainable improvement. Soc. Reprod. Fertil. Suppl. 6:237-254. https://doi.org/10.5661/RDR -VI-237.

Lucy, M. C., G. A. Verkerk, B. E. Whyte, K. A. Macdonald, L. Burton, R. T. Cursons, J. R. Roche, and C. W. Holmes. 2009. Somatotropic axis components and nutrient partitioning in genetically diverse dairy cows managed under different feed allowances in a pasture system. J. Dairy Sci. 92:526-539. https://doi.org/10.3168/ jds.2008-1421.

Lyimo, Z. C., M. Nielen, W. Ouweltjes, T. A. Kruip, and F. J. van Eerdenburg. 2000. Relationship among estradiol, cortisol and intensity of estrous behavior in dairy cattle. Theriogenology 53:17831795. https://doi.org/10.1016/S0093-691X(00)00314-9.

Moore, S. G., S. B. Cummins, S. Mamo, P. Lonergan, T. Fair, and S. T. Butler. 2019. Genetic merit for fertility traits in Holstein cows: VI. Oocyte developmental competence and embryo development. J. Dairy Sci. 102:4651-4661. https://doi.org/10.3168/jds 2018-15813.

Moore, S. G., T. Fair, P. Lonergan, and S. T. Butler. 2014a. Genetic merit for fertility traits in Holstein cows: IV. Transition period, uterine health, and resumption of cyclicity. J. Dairy Sci. 97:27402752. https://doi.org/10.3168/jds.2013-7278.

Moore, S. G., A. O'Gorman, L. Brennan, T. Fair, and S. T. Butler. 2017. Follicular fluid and serum metabolites in Holstein cows are predictive of genetic merit for fertility. Reprod. Fertil. Dev. 29:658 669. https://doi.org/10.1071/RD15182.

Moore, S. G., S. Scully, J. A. Browne, T. Fair, and S. T. Butler. 2014b. Genetic merit for fertility traits in Holstein cows: V. Factors affecting circulating progesterone concentrations. J. Dairy Sci. 97:5543-5557. https://doi.org/10.3168/jds.2014-8133.

Norman, H. D., J. R. Wright, S. M. Hubbard, R. H. Miller, and J. L. Hutchison. 2009. Reproductive status of Holstein and Jersey cows in the United States. J. Dairy Sci. 92:3517-3528. https://doi.org/ 10.3168/jds.2008-1768.

NRC. 2001. Nutrient Requirements of Dairy Cattle. 7th rev. ed. Natl. Acad. Sci., Washington, DC.

Ospina, P. A., D. V. Nydam, T. Stokol, and T. R. Overton. 2010. Associations of elevated nonesterified fatty acids and beta-hydroxybutyrate concentrations with early lactation reproductive performance and milk production in transition dairy cattle in the northeastern United States. J. Dairy Sci. 93:1596-1603. https:// doi.org/10.3168/jds.2009-2852.

Palmer, M. A., G. Olmos, L. A. Boyle, and J. F. Mee. 2010. Estrus detection and estrus characteristics in housed and pastured Holstein-Friesian cows. Theriogenology 74:255-264. https://doi.org/ 10.1016/j.theriogenology.2010.02.009.

Ribeiro, E. S., R. G. Bruno, A. M. Farias, J. A. Hernández-Rivera, G. C. Gomes, R. Surjus, L. F. Becker, A. Birt, T. L. Ott, J. R Branen, R. G. Sasser, D. H. Keisler, W. W. Thatcher, T. R. Bilby, and J. E. Santos. 2014. Low doses of bovine somatotropin enhance conceptus development and fertility in lactating dairy cows. Biol. Reprod. 90:10. https://doi.org/10.1095/biolreprod.113.114694.

Rojas Canadas, E., M. M. Herlihy, J. Kenneally, J. Grant, F. Kearney, P. Lonergan, and S. T. Butler. 2020. Associations between postpartum phenotypes, cow factors, genetic traits, and reproductive performance in seasonal-calving, pasture-based lactating dairy cows. J. Dairy Sci. 103:1016-1030. https://doi.org/10.3168/jds 2018-16001.

Rutherford, A. J., G. Oikonomou, and R. F. Smith. 2016. The effect of subclinical ketosis on activity at estrus and reproductive performance in dairy cattle. J. Dairy Sci. 99:4808-4815. https://doi.org/ 10.3168/jds.2015-10154.

Santos, J. E., R. S. Bisinotto, and E. S. Ribeiro. 2016. Mechanisms underlying reduced fertility in anovular dairy cows. Theriogenology 86:254-262. https://doi.org/10.1016/j.theriogenology.2016.04.038.

Santos, J. E., R. S. Bisinotto, E. S. Ribeiro, F. S. Lima, L. F. Greco, C. R. Staples, and W. W. Thatcher. 2010. Applying nutrition and physiology to improve reproduction in dairy cattle. Soc. Reprod. Fertil. Suppl. 7:385-403. https://doi.org/10.5661/RDR-VII-387.

Schirmann, K., N. Chapinal, D. M. Weary, L. Vickers, and M. A. G. von Keyserlingk. 2013. Short communication: Rumination and feeding behavior before and after calving in dairy cows. J. Dairy Sci. 96:7088-7092. https://doi.org/10.3168/jds.2013-7023.

Silper, B. F., A. M. L. Madureira, M. Kaur, T. A. Burnett, and R. L. A. Cerri. 2015. Short communication: Comparison of estrus characteristics in Holstein heifers by 2 activity monitoring systems. J. Dairy Sci. 98:3158-3165. https://doi.org/10.3168/jds.2014-9185.

Snijders, S. E. M., P. G. Dillon, K. J. O'Farrell, M. Diskin, A. R. G. Wylie, D. O'Callaghan, M. Rath, and M. P. Boland. 2001. Genetic merit for milk production and reproductive success in dairy cows. Anim. Reprod. Sci. 65:17-31. https://doi.org/10.1016/S0378 $-4320(00) 00217-7$.

Vailes, L. D., and J. H. Britt. 1990. Influence of footing surface on mounting and other sexual behaviors of estrual Holstein cows. J. Anim. Sci. 68:2333-2339. https://doi.org/10.2527/1990.6882333x.

Valenza, A., J. O. Giordano, G. Lopes Jr., L. Vincenti, M. C. Amundson, and P. M. Fricke. 2012. Assessment of an accelerometer system for detection of estrus and treatment with gonadotropin-releasing hormone at the time of insemination in lactating dairy cows. J. Dairy Sci. 95:7115-7127. https://doi.org/10.3168/jds.2012-5639.

Veronese, A., O. Marques, R. Moreira, A. L. Belli, R. S. Bisinotto, T. R. Bilby, F. Peñagaricano, and R. C. Chebel. 2019a. Genomic merit for reproductive traits. I: Estrous characteristics and fertility in Holstein heifers. J. Dairy Sci. 102:6624-6638. https://doi.org/10 $.3168 /$ jds.2018-15205.

Veronese, A., O. Marques, F. Peñagaricano, R. S. Bisinotto, K. G. Pohler, T. R. Bilby, and R. C. Chebel. 2019b. Genomic merit for reproductive traits. II: Physiological responses of Holstein heifers. J. Dairy Sci. 102:6639-6648. https://doi.org/10.3168/jds.2018 -15245 .

Weber, W. J., C. R. Wallace, L. B. Hansen, H. Chester-Jones, and B. A. Crooker. 2007. Effects of genetic selection for milk yield on somatotropin, insulin-like growth factor-I, and placental lactogen in Holstein cows. J. Dairy Sci. 90:3314-3325. https://doi.org/10 $.3168 /$ jds.2006-899.

\section{ORCIDS}

Ricardo C. Chebel ๑ https://orcid.org/0000-0002-9700-8089 